\title{
DESCENTRALIZAÇÃO \\ POLÍTICO-ADMINISTRATIVA DA EDUCAÇÃO \\ NO BRASIL: ENTRE VELHOS E NOVOS \\ PARADIGMAS
}

Wilson Alves de Paiva*

\section{RESUMO}

Este texto tem como objetivo principal contribuir com a discussão em torno da descentralização político-administrativa da educação brasileira. $\mathrm{O}$ autor inicia sua análise nas tendências descentralizadoras do Período Colonial. Analisa o fortalecimento dessas tendências ao longo dos séculos e os diferentes paradigmas que as têm norteado. E finaliza analisando o papel atual do município diante das mudanças sociais, políticas e educacionais dos últimos anos. O estudo de documentos e livros que tratam do assunto leva a concluir que, apesar de antiga, a luta agora traz novos paradigmas e propõe fatos inusitados.

Palavras-chave: municipalização, descentralização, paradigmas educacionais, LDB.

A situação da educação municipal no Brasil nos dias atuais, no que concerne às políticas públicas e gestão, representa, por um lado, o fortalecimento dos movimentos democráticos e das idéias de descentralização, além de maior participação popular, cujas raízes vão desde as revoltas dos colonos contra a Coroa Portuguesa até as últimas lutas contra um regime militar extremamente centralizador e

\footnotetext{
* Professor da Faculdade de Educação da Universidade Federal de Goiás (UFG); exsecretário municipal de Educação de Trairão-PA; assessor técnico da Secretaria Executiva de Educação do Pará (Seduc) e consultor em Educação Municipal. Graduado em Pedagogia e pós-graduado em Psicopedagogia. E-mail: wp@riotapajos.com.br
} 
repressor. Por outro lado, a descentralização político-educacional consagrada na atual Constituição e na Lei de Diretrizes e Bases da Educação (LDB) pode estar inserida nas políticas neoliberais que imprimem uma flexibilização social e preconizam a diminuição da ação do Estado na vida pública. Entre os velhos e os novos paradigmas a ação popular tem sido âncora de resistência e deve ser o vetor primordial da gestão educacional diante dos limites e possibilidades que o conjunto de leis oferece.

No tempo da colônia, o interesse direto dos portugueses era tirar o máximo de proveito da nova terra para garantir a existência do reino, bem como sua prosperidade. Não havendo nenhum aparelhamento governamental no primeiro século de ocupação, o soberano $\mathrm{D}$. João IV criou em 1640 o Conselho Ultramarino, cujo objetivo principal era tomar as rédeas da administração para fortalecer o poder real, subordinando os donatários (senhores feudais à brasileira) a um governo geral, e posteriormente, às ordens diretas de Lisboa. A luta pela sobrevivência da Coroa e de suas instituições governamentais, que resultou em centralização de poder, pode ser entendida através de dois pontos fundamentais: a necessidade de afirmar-se como nação soberana, tendo em vista o longo período de dependência em relação ao governo espanhol, e a perda de legitimidade das autoridades lusitanas, inclusive em sua dinâmica interna, com o declínio do poder das lideranças municipais em Portugal. Sobre isso nos diz Caio Prado Júnior (1994, p. 51):

As Câmaras, em Portugal, já tinham perdido a maior parte de sua importância quando se iniciou a colonização do Brasil. Mas suas congêneres da colônia adquirirão, desde logo, um poder considerável. É fácil explicá-lo pelo isolamento em que viviam os colonos e a debilidade de uma administração longínqua e mal representada aqui por donatários indiferentes por tudo quanto não fosse a percepção de proveitos pecuniários. Grande parte dos negócios públicos, inclusive matérias relevantes de caráter geral, eram tratados e resolvidos nas Câmaras, que chegaram num momento a legislar sobre quase todos os assuntos governamentais. 
Na verdade o intento das câmaras brasileiras era promover a participação do poder local, de modo a definir seus próprios rumos e não ficar atadas a uma administração ausente, distante e que tinha pouco a oferecer. Nesse período a colônia podia contar com juízes ordinários, de eleição popular, cuja função primordial era presidir as câmaras e que possuíam certa autonomia política fundada na razão democrática. Entretanto, no primeiro viés desse processo, os juízes de fora, nomeados pelo rei, substituíram os juízes ordinários, e os vereadores passaram a ser também escolhidos pela vontade régia. Dessa forma, o regime político de centralização permaneceu por todo o Período Colonial, sufocando os anseios descentralizadores que surgiram em muitas partes do território. A independência, proclamada em 1822, em vez de representar uma significativa descentralização, resultou em uma recentralização no poder pessoal do imperador. Abafaram-se assim as idéias liberais e a influência da burguesia urbana, que só posteriormente conseguiu forçar a criação das câmaras municipais, em 1824, e a figura de um prefeito, no estilo francês, em 1835. Tais fatos deram uma significativa, porém não real autonomia administrativa aos municípios. As constituições de 1891, 1934 e 1937 foram omissas quanto ao assunto, cabendo à Constituição de 1946, sob influência de Anísio Teixeira, assegurar a autonomia municipal. Como afirma Campos (1987, p. 17),

a Proclamação da República em si não pode ser caracterizada como
uma ruptura ou um fator de mudança na política brasileira [...]. Nas
mudanças político-institucionais procedidas, um elemento pode
ser apontado como marco diferencial dos períodos Império e Re-
pública: passar o Estado-Membro a ser a unidade básica da polí-
tica brasileira. Na verdade, o sistema federativo, contrapondo-se
à centralização imperial, se apresenta como capaz de solucionar
os problemas mais urgentes do país.

A descoberta do "novo mundo" transpôs para aqui não só as disputas estritamente relacionadas ao poder político como o descaso governamental pela educação. Entregues aos clérigos dos mosteiros para a formação devocional e aos nobres para a educação cavalheiresca numa minúscula porcentagem, os portugueses ignoravam a 
necessidade de fornecer as primeiras letras a toda a população infantil. Coube, portanto, à Companhia de Jesus, órgão da Contra-Reforma, a tarefa de promover a educação dos povos d'além-mar. Os jesuítas vieram para o Brasil chefiados por Manoel da Nóbrega em 1549. Nos 210 anos de sua permanência no país, além da formação de sacerdotes e da educação dos nobres, estabeleceram contatos com os índios, fundaram aldeamentos e vilas e foram ativos na exploração comercial e acumulação de terras e riquezas inigualáveis. Seu pujante enriquecimento e poder foi a gota d'água para a expulsão da Ordem pelo marquês de Pombal (Sebastião de Carvalho e Melo), ministro dos Negócios Estrangeiros, cujos planos de "civilizar" a colônia traduziam as aspirações européias em voga: humanização e laicidade. O Diretório de 1757 veio inaugurar o regime estatal e laico do ensino, cuja manutenção ficou sob a responsabilidade do governo da própria colônia, por meio do "subsídio literário", imposto cobrado dos açougues e das destilarias. As "aulas-régias" inauguraram, dessa forma, a educação pública estatal no Brasil, um novo período histórico em que a ação do Estado poderia convergir para a organização de um sistema. Se para muitos isso significou um avanço, para Prado Júnior (1994, p. 90-91),

não se pode considerar sistema de ensino as magras cadeiras de primeiras letras, latim e grego, que havia nalguns dos maiores centros da colônia. Criadas aliás só depois de 1776, e que funcionavam ao deus-dará, com professores mal pagos, alunos indisciplinados e aulas desorganizadas. O nível cultural da colônia era da mais baixa e crassa ignorância.

O objetivo de Pombal parece ter sido tão-somente o de conter o crescimento de uma ordem religiosa que, principalmente em terras brasileiras, passou a acumular riqueza e poder. Os lucros da companhia chegaram a representar $25 \%$ do PIB colonial e, para ilustração, só na fazenda Santa Cruz, do Colégio do Rio de Janeiro, ela possuía 75 mil cabeças de gado. A estrutura criada pela companhia tirava das mãos da Coroa o poder de decisão no âmbito local e regional. 
Durante o Império e a República ressurgem as bases municipalistas que se têm tornado uma tradição brasileira. Seu ideal formulador está ligado diretamente à tradição municipalista européia e, mais propriamente, portuguesa, seguindo as aspirações da implantação do regime liberal em Portugal em 1833.

Podemos dizer que vários foram os caminhos para chegar ao estágio de organização político-administrativa em que nos encontramos atualmente. Diversas tentativas de descentralização foram frustradas ao longo da história, desde os movimentos mais abrangentes contra a Coroa, contra o autoritarismo e a centralidade do poder, como a Inconfidência Mineira, Farroupilhas, Cabanagem e outros também importantes, até os estritamente político-educacionais, como as reformas Francisco Campos e Sampaio Dória.

O século XIX testemunhou o crescimento do debate sobre a descentralização como resultado do sentimento republicano e sobre a necessidade de escolarização dos habitantes das províncias, cujas assembléias provinciais intensificavam suas atividades legislativas nesse sentido. Diversas leis surgiram para, logo em seguida, tornarem-se inoperantes diante da falta de recursos financeiros e da ineficiência do Estado. O grande exemplo está na lei de 15 de novembro de 1827 , considerada a primeira lei da educação, que dizia em seu artigo $1^{\circ} .:$ "em todas as cidades, vilas e lugares mais populosos haverá escolas de primeiras letras que forem necessárias". Não havia um sistema nacional de educação centralizado, como os existentes nos países europeus nesse período. Dessa forma as províncias promoveram a instituição de "sistemas provinciais", sob a influência do ideário civilizatório iluminista, tendo como objetivo maior instruir as "classes inferiores". Com a falta de professores, o método utilizado, entre outros, foi o "lancasteriano" ou "mútuo", que atingia um grande número sem muitos gastos. A expansão do ensino era a bandeira de luta da sociedade. A população, por sua vez, mobilizou-se com aberturas de escolas domésticas, como resultado do grande debate sobre o problema da instrução iniciado logo após a proclamação da República pelos militares e intelectuais liberais. Em razão desse debate, o início do século foi inundado por ideais iluministas e positivistas que mobilizaram as oligarquias, de modo a gerar um "entusiasmo pela educação" 
que coincidia com o entusiasmo pelo desenvolvimento. Mas a ideologia desenvolvimentista e seu gigantismo também fortaleceram o conceito de centralidade de poder, burocracia e autoritarismo, apesar de promover a expansão da rede de ensino básico, superior e técnicoprofissional (Senai e Senac) e criar dotação orçamentária (Constituição de 1934) e órgãos de gerenciamento (Mesp).

O lema "mais escolaridade e menos criticidade", dos anos 30 e 40, foi perdendo espaço para os debates sobre a qualidade do ensino e sobre a ideologia reinante, surgidos nas décadas de 1950 e 1960. A Ubes e a UNE, ligadas aos partidos de esquerda, mobilizaram estudantes em todo o país, e juntamente com os intelectuais, estes reclamavam uma maior participação, qualidade, gratuidade, descentralização e participação democrática.

Em 1964, os "subversivos" foram silenciados, perseguidos, exilados e torturados. Começou aí o governo militar, cuja ação significou um congelamento nas negociações e conquistas democráticas. O "descongelamento" só teve início na década de 1980 quando alguns fatos, como a anistia, o pluripartidarismo, os movimentos populares, as eleições diretas, o fortalecimento do Legislativo e as leis liberais, passaram a configurar um fin-de-siècle mais promissor e com uma temática que apontou para o fim do autoritarismo e a implantação plena da democracia.

Se não atingimos até agora tal patamar, a euforia ainda não se dissipou totalmente, e os últimos acontecimentos políticos e educacionais se direcionam para a concretização desse sonho antigo. Vale ressaltar também a mobilização cada vez maior da sociedade no sentido de participar, analisar, criticar e propor alternativas. Se a atual LDB e a atual Constituição não representam a plena aspiração de quem carrega o sonho, significam muitos passos à frente e uma abertura considerável com respeito à legislação.

A essa altura é conveniente indagar se tais fatos constituem paradigmas de uma sociedade pós-moderna, fundamentada numa nova racionalidade, cujo princípio básico seja o espírito democrático e participativo; ou se morbidamente revelam uma crise paradigmática na qual a luta histórica "descentralização versus centralização" encontra-se engodada por um discurso ludibriador. Todavia, tomando 
como pressuposto que o que vivenciamos hoje é a consolidação dos ideais democráticos incorporados à idéia da autogestão pública, da participação do poder local e da valorização da cultura regional e comunitária, isso nos faz lembrar os primeiros colonos. O sonho talvez tenha se originado durante o período da colonização, quando os agricultores, mineiros ou comerciantes aqui estabelecidos intentaram uma certa descentralização e um fortalecimento do poder local através das câmaras e dos já citados juízes ordinários. Não foi um ato revolucionário, mas uma estratégia política e uma "ação possível" diante da adversa situação em que se encontravam. Muitas "ações possíveis" aconteceram durante a história e ainda podem acontecer na atualidade. Mesmo que não haja uma revolução, muitas dessas ações podem ser transformadas em resultados significativos no processo de democratização e melhoria da qualidade do fenômeno educacional. A própria legislação atual demonstra certos avanços resultantes de conquistas históricas, como o avanço da vertente municipalista e descentralizadora sempre presente na política brasileira. As primeiras LDBs e as constituições republicanas deram alguns passos tímidos em favor do município, mas o avanço considerável só foi previsto na Constituição Federal de 1988, que incorporou um certo "espírito" de descentralização, diversificação e aspiração democrática. O primeiro artigo do capítulo que trata da educação estabelece logo a colaboração da sociedade. E o ideal seria que essa colaboração significasse não apenas a organização de grupos de acompanhamento e controle (como é o caso dos conselhos da merenda escolar e outros), mas uma participação integral, suprapartidária e comprometida com os anseios populares.

Essa é uma interpretação bastante otimista, pois a colaboração da sociedade poderá, de outra forma, resultar na diminuição da ação obrigatória do Estado na oferta e manutenção de um direito adquirido. Desse modo, a colaboração jamais pode prescindir da ação fiscalizadora, necessária à gestão dos recursos públicos. O inciso VI do artigo 206 fala da gestão democrática do ensino público, e o artigo 211 possibilita a autonomia municipal na criação do "sistema": 
Art. 211. A União, os Estados, o Distrito Federal e os Municípios organizarão em regime de colaboração seu sistema de ensino.

$\S 1^{\circ}$. [...]

$\S 2^{\circ}$. Os municípios atuarão prioritariamente no ensino fundamental (1 ${ }^{\circ}$.grau) e na educação infantil. (Brasil, 1999, p. 100)

Mesmo não sendo uma ação obrigatória, a tendência dos municípios tem sido a da assinatura do convênio de municipalização com os estados para receber deles as escolas de educação infantil e nível fundamental. A criação do Fundo Nacional de Desenvolvimento do Ensino Fundamental (Fundef) contribuiu nesse processo tendo em vista o caráter redistributivo do valor referencial por aluno. Ou seja, quanto maior o número de alunos, maior a quantidade da verba recebida. Em regiões de baixa densidade demográfica e fonte arrecadadora insuficiente, como a Região Norte, houve ao longo da década de 1990 um processo denominado estadualização do ensino, que consistia na transferência de escolas municipais para o Estado a fim de diminuir gastos com a folha de pagamento e com a manutenção dessas escolas. A criação do Fundef e as orientações da Constituição e da LDB vieram reverter esse quadro. Em 2001 a situação da municipalização no Estado do Pará era a seguinte:

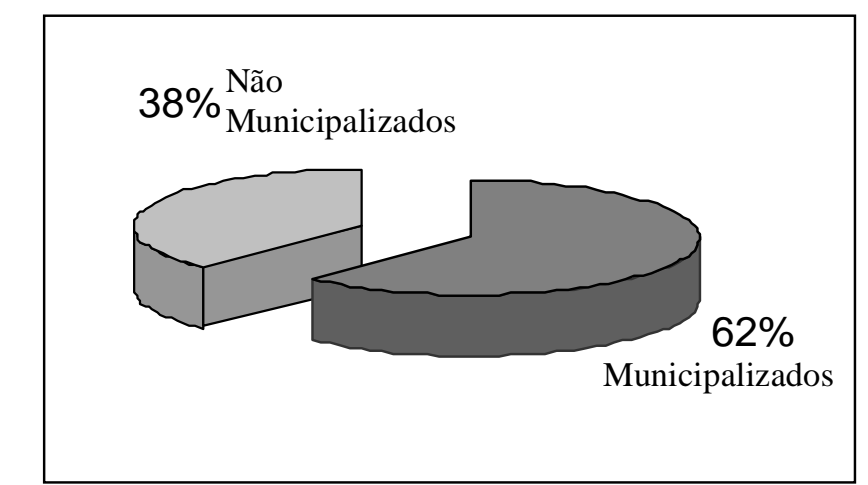

Fonte: Dados fornecidos pessoalmente pelo Setor de Estatística da Secretaria Executiva de Educação (Seduc) do Pará 
Tais fatos vêm refletir, de uma forma ou de outra, a via municipalista adotada pela política brasileira como resultado de aspirações antigas e incorporadas na luta pelo reconhecimento do poder local, da participação popular e gestão mais aproximada. Vale lembrar que após a votação da Constituição Federal, em 1988, o Congresso iniciou uma ampla discussão sobre as diretrizes da educação nacional, cujo eixo passou a ser a universalização do ensino fundamental e a organização de um sistema nacional, assegurando a articulação orgânica nas esferas federal, estadual e municipal. Vários encontros, como a IV Conferência Brasileira de Educação (CBE) de 1986, que elaborou a Carta de Goiânia, e a V CBE, que elaborou a Carta de Brasília, serviram de subsídio à elaboração do texto das diretrizes nacionais. As iniciativas governamentais tiveram como referência a "Declaração Mundial sobre Educação para Todos", proclamada no encontro de Jontien, na Tailândia, de 5 a 9 de março de 1990, o qual utiliza termos como "Plano Decenal, educação básica, educação fundamental" etc.

Finalmente em 25 de outubro de 1995, o plenário aprovou o Substitutivo Darcy Ribeiro, que, após as alterações, culminou na aprovação da redação final da nova LDB em 17 de dezembro de 1996, e na respectiva sanção em 20 de dezembro de 1996, com o número 9.394/1996, em cerimônia no Palácio do Planalto, e com o nome de Lei Darcy Ribeiro.

Quanto aos avanços gerais dessa lei, as opiniões divergem consideravelmente, mas num aspecto todos estão de acordo: foi a única que nasceu no seio do Poder Legislativo, significando um avanço rumo à democracia. Para Pedro Demo (1997, p.10), a lei não é inovadora e

não teria qualquer condição de passar com um texto "avançado", no sentido de ser a lei dos sonhos do educador brasileiro. Como o Congresso Nacional é sobretudo um "pesadelo", as leis importantes não podem deixar de sair com sua cara e são, pelo menos em parte, também um pesadelo. Lei realmente "boa" só pode provir de um Congresso “bom”. Não é, obviamente, nosso caso, pelo menos por enquanto. 
76 PAIVA, Wilson A. Descentralização político-administrativa da...

Para outros,

a atual Lei de Diretrizes e Bases da Educação Nacional introduz mudanças significativas na educação básica de nosso país. Importantes avanços, resultantes da participação da sociedade civil, na etapa inicial de construção da lei, foram consagrados, apesar do longo e conflituoso processo de sua tramitação no Congresso Nacional e das inúmeras tentativas de eliminar as conquistas obtidas. (Pereira e Teixeira, 2000, p. 87)

Assim, levados pela retórica dos eufóricos, podemos dizer que, ao adentrarmos uma nova era, torna-se extremamente necessário que a gestão municipal amplie seus horizontes a fim de contemplar a dimensão real do processo de descentralização política no campo educacional. Both (1997, p. 78 e 185) nos diz que

quando se trata da municipalização da educação, por certo sua abrangência ultrapassa os simples limites do ensino, alargandose a outras áreas de cunho social para, em conjunto, compor aquilo que se pode denominar educação [Nessa análise, a importância do município é fundamental, pois este], como base da sociedade, certamente se constitui no centro para onde todas as atenções devem convergir [grifos do autor].

Entretanto, é importante analisar que nessa convergência de atenções o processo de descentralização possui duas vertentes básicas: por um lado, o desejo de participação e autonomia por parte da população como resultado do movimento pela democracia na política brasileira; mas, por outro, podemos verificar de forma clara a influência das tendências neoliberais das sociedades capitalistas que preconizam a política do Estado Mínimo, cuja implantação pode-se dar por meio da privatização dos setores produtivos administrados pelo Estado e, por conseguinte, da "mercadologização" dos aspectos sociais. Já existe na escola uma invasão de termos como "qualidade total," "clientela," "retorno financeiro," e outros que evocam a idéia de mer- 
cado, sem deixar de mencionar aqui os embustes da mídia: Amigos da escola, Voluntários, Padrinhos etc.

Entretanto, a descentralização tem-se tornado um processo dialético. Podemos afirmar que esse conflito tem contribuído para uma maior discussão e o amadurecimento do processo democrático e da própria gestão educacional do município nas dimensões políticas e pedagógicas. As vertentes neoliberais, por sua vez, forçam uma flexibilização social, fugindo das velhas formas de organização fordista/ taylorista da produção e imprimem, cada vez mais, uma dinamicidade nos meios econômico, cultural e educacional a ponto de provocar qualidade, acessibilidade e democratização. As vertentes populares, representadas pela força sindical, pelas organizações não-governamentais (ONGs), igrejas e associações diversas, por sua vez, reclamam mais espaço nas decisões político-administrativas e reivindicam melhores condições de trabalho, salários mais dignos, gratificações e outros direitos que têm culminado no cumprimento, por parte dos gestores, do espírito das novas leis. A implantação do plano de carreira, do projeto pedagógico, dos conselhos, da eleição para diretores de escolas, do pagamento de hora-atividade e abonos e da qualificação do profissional da educação constituem alguns resultados positivos desse processo.

Fundamentalismo à parte, o que se pode estabelecer é uma política de construção de canais comunicativos entre as representações populares e os gestores, proporcionando uma construção coletiva do processo educacional.

Só podemos ganhar uma luta se entrarmos nela, tentando modificar-lhe o sentido, transformar a negatividade em positividade. Não nos omitindo, não batendo o pé, constantemente, e dizendo "não". O que ganhamos com isso? Ganhamos que a direita privatista diz "sim" e acaba se apoderando das verbas que poderiam ser destinadas ao serviço público. Não se trata, portanto, de dizer apenas "sim" ou "não", como em anos passados se disse "não" à profissionalização, "não" à "informatização" etc., pois acabou-se dizendo "não" à mudança. (Gadotti e Romão, 1993, p. 64) 
78 PAIVA, Wilson A. Descentralização político-administrativa da...

A observação de Gadotti põe em xeque posicionamentos extremados que procuram rejeitar aspectos ligados à produção capitalista, como qualidade, informatização e uso de outras tecnologias; e ainda toda e qualquer iniciativa que vem de órgãos governamentais, como o MEC e as secretarias estaduais e municipais de educação. Mas põe em xeque também as práticas coniventes da política privatista. Aqui reside o ponto crucial da gestão municipal da educação, porque a inapetência administrativa pode contribuir para essas tendências ou acatar de forma acrítica qualquer mudança proclamada. No campo das decisões políticas verifica-se atualmente uma tendência à "prefeiturização" do processo educacional e, por conseguinte, uma transferência de poder centralizador da União ou do Estado para a prefeitura, pura e simplesmente. Outro agravante pode ser a ocorrência de uma política clientelista em nível local ou estadual; ou ainda a já citada possível terceirização em nível macro, que culminaria com os objetivos socioeconômicos privatizadores da política neoliberal.

Partindo dessas afirmações, portanto, a autonomia passa a ser a condição sine qua non do processo de descentralização. Autonomia, como status de autogestão do município, resultante do processo dialógico de todas as partes envolvidas na educação municipal. Situação que pode, no futuro, possibilitar a autogestão da escola, tão proclamada por Gadotti.

A descentralização por si só "não é boa ou má, indicável ou contra-indicável" (Chiavenato, apud Both, 1997, p. 90), mas depende de certos fatores decisivos: personagens envolvidas, competência dos subordinados, confiança dos superiores nessa competência, facilidade de informações que permitam tomada de decisões e, principalmente, o grau de respaldo político da administração pública a todos os envolvidos no processo. Depende ainda do grau de seriedade, competência e idealismo do gestor municipal e do gestor educacional. Acrescentamos aqui a importância da capacidade de participação e reivindicação por parte dos diversos setores e segmentos sociais. Talvez seja premente a adoção de uma postura durkheimiana, aquela que trabalha a estrutura da vida social no conceito de solidariedade 
como força vital para a manutenção da coesão social ou do "contrato social", de Rousseau (2001).

Entre o medo e a euforia nesse processo, situam-se a incerteza e a insegurança, pois à frente tanto pode estar um gestor comprometido, ético, responsável e dinâmico, como um prefeito ou um secretário de educação incapaz de entender as mudanças que se efetivam na atualidade. O medo é gerado por causa dos possíveis "efeitos colaterais" que imprimem um aspecto negativo ao todo. Algumas ações de governantes municipais vêm revelar um posicionamento político impregnado de práticas grotescas, perseguição política, demissões, autoritarismo, redução salarial, nepotismo e outras práticas que se situam na "velha ordem" das coisas, ou seja, na política coronelista e clientelista das oligarquias, que dominou os séculos XIX e XX, bem como práticas específicas do período Vargas e da ditadura militar a partir de 1964. Muitos prefeitos, filhos dessa "ideologia" e frutos dessa concepção de estrutura político-social, tendem a exercer uma gestão em tais moldes e acabam gerando, por um lado, um retrocesso no movimento de democratização da educação brasileira; e, por outro, o esvaziamento dos organismos representativos de classe.

O agravante maior na produção de incertezas está no fato de que os municípios passaram a receber do Estado uma estrutura educacional bem deficiente, necessitando de investimentos, quando têm seus cofres vazios. Número insuficiente de escolas, estrutura física e mobiliário deteriorados, equipamentos avariados e outros fatores somam-se aos problemas de que o Estado talvez tenha procurado se livrar o mais depressa possível. No caso de regiões carentes, como o Nordeste e o Norte, a municipalização tem encontrado ainda obstáculos em relação aos recursos humanos, porque, em muitos de seus municípios, as pessoas disponíveis não possuem sequer formação de segundo grau, e há professores com a quarta série primária lecionando para a mesma série. Dessa forma, podemos inferir que

encontramo-nos num momento crucial de mudança social, quando se estabelecem as bases de uma nova ordem pós-industrial que alguns analistas sociais qualificam também de pós-capitalista 
(Jameson, por exemplo). O papel dos centros de ensino, nesse novo marco, está ainda por ser determinado. Para nós, corresponde manter viva a memória histórica dos avanços e retrocessos, refletir e ensaiar novas vias alternativas. Repensar a escola no marco da modernidade pode nos ajudar a encarar o futuro com maior lucidez. (Costa, 2000, p. 144)

Portanto, o papel do município está ainda por ser determinado, definido de forma clara e objetiva. Cabe ao gestor municipal compreender a dimensão desse processo e empregar esforços para implantar políticas públicas, tendo em vista a melhoria da qualidade do ensino, a ampliação do acesso escolar, a valorização do magistério e a renovação nas práticas pedagógicas cujo fim maior seja a promoção da cidadania. $\mathrm{Ou}$ o órgão diretor educacional - Secretaria Municipal de Educação (Semec) - fundamenta as bases dessa política com a devida seriedade e responsabilidade, ou a descentralização poderá significar aquilo que os frankfurtianos denunciaram: a ação dos manipuladores por trás da falsa participação popular. Toda situação é ambígua, e em todos os trâmites da administração pública pode haver uma boa ou uma má gestão. Mas, com a municipalização, o gestor passa a estar mais próximo do público envolvido, e a população pode utilizar sua força na reivindicação de seus direitos, como acentuam Gadotti e Romão (1993):

Defendo a educação municipal [...] porque defendo a descentralização da educação, a [...] autogestão educativa, o controle da população sobre o processo de ensino e uma concepção popular da escola. ( p. 6)

A questão está em termos uma sociedade civil, um movimento social, popular e sindical em favor da educação, suficientemente fortes para atingir o quanto antes um alto nível de escolarização. Qualquer possibilidade que aponte nessa direção deve ser bemvinda e não combatida. (p. 65).

Demo (2001, p. 17) complementa: “educação é coisa tão importante que só pode ser bem feita sob as vistas dos interessados diretamente; ou seja, o lugar mais apropriado da organização educacional, no fundo, é o município". 
Nesse aspecto, podemos dizer que a resposta aos anseios que a nova era proporciona dependerá diretamente da população do município. É ela que escolhe o seu gestor e que pode acompanhar o gerenciamento de seu representante. Dependerá do uso da proximidade que ela tenha com a administração pública e da força que ela possa empregar na reivindicação de um compromisso com as aspirações populares, com a transparência e com a responsabilidade. Entretanto, o fato de alguém ser um elemento político e ativista não garante que esteja engajado nas dinâmicas e ações que apontam para esse rumo. $\mathrm{O}$ processo exige um ato consciente, responsável e de acordo com os anseios de participação da coletividade. Exige, portanto, uma consciência que vá além do senso comum e que não se esgote na dicotomia tradicional entre "direita" e "esquerda", mas que objetive construir um canal de consenso através do diálogo com todos os envolvidos nesse processo.

Diante de tais constatações e considerações, um novo sentido se põe para a interpretação do processo histórico, do posicionamento político e da administração da educação. Novas exigências se impõem às políticas educacionais, para que respondam de forma comprometida, ampla e efetiva às necessidades reais e urgentes aqui levantadas. Eis o desafio atual: possibilitar, pelo trabalho de gestão, uma descentralização cujos paradigmas sejam a democratização da educação pública, a participação popular e a promoção da qualidade, de forma a propiciar uma realização pessoal e coletiva que venha promover verdadeiramente a cidadania.

\section{ABSTRACT}

This text main objective is to contribute with the discussion around the political-administrative decentralization of Brazilian education. The author begins his analysis in the decentralizing tendencies of the Colonial Period. He analyzes the invigoration of that tendency along the centuries and the different paradigms that have been orientating it. And he concludes analyzing the current role of the municipal district before the social, politic and educational changes of the last years. The study of documents and books that deal with the matter points to 
a conclusion that, in spite of old, the strive now brings new paradigms and it proposes unexpected facts.

Keywords: municipalization, decentralization, educational paradigms, education laws.

\section{REFERÊNCIAS}

BOTH, Ivo José. Municipalização da educação: uma contribuição para um novo paradigma de gestão do ensino fundamental. Campinas, SP: Papirus, 1997. (Coleção Magistério: Formação e Trabalho Pedagógico).

BRASIL. Constituição Federal de 1988. Rio de Janeiro: FAE, 1989.

BRASIL. Lei 9.394/1996. Disponível em: <http://www.mec.gov.br/ leis> Acesso em: 28 jul. 2002.

CAMPOS, Francisco Itami. Coronelismo em Goiás. 1 ${ }^{\text {a }}$. reimpressão. Goiânia, Ed. da Universidade Federal de Goiás, 1987.

COSTA, Maria Vorraber. (Org.). Escola básica na virada do século: cultura, política e currículo. 2. ed. São Paulo: Cortez, 2000.

DAMASCENO, Alberto. Origens da educação estatal na América Portuguesa. 1998. Tese (Doutoramento) - Pontifícia Universidade Católica de São Paulo, São Paulo.

DEMO, Pedro. A nova LDB: ranços e avanços. Campinas, SP: Papirus, 1997.

FERREIRA, Naura Syria Carapeto. (Org.). Gestão democrática da educação: atuais tendências, novos desafios. 2. ed. São Paulo: Cortez, 2000.

GADOTTI, Moacir; ROMÃO, José Eustáquio. (Org.). Município e educação. São Paulo: Cortez, 1993.

GADOTTI, Moacir. Escola cidadã. 6. ed. São Paulo: Cortez, 2000. (Coleção Questões da Nossa Época, v. 24). 
LUZURIAGA, Lorenzo. História da educação e da Pedagogia. Tradução de Luiz Damasco Pena e J. B. Damasco Pena. São Paulo: Nacional, 1976.(Atualidades Pedagógicas, v. 59).

MONLEVADE, João A. C. Educação pública no Brasil: contos e descontos. Brasília: Idéia, 1997.

PEREIRA, W. P.; TEIXEIRA, Z. A. A educação básica redimensionada. In: BRZEZINSKI, I. (Org.). LDB interpretada: diversos olhares se entrecruzam. 4. ed. São Paulo: Cortez, 2000.

PRADO JÚNIOR, Caio. História econômica do Brasil. 41. ed. São Paulo: Brasiliense, 1994.

ROUSSEAU Jean-Jacques. Do contrato social. São Paulo: Martin Claret, 2001.

SAVIANI, Dermeval. Da nova $L D B$ ao novo Plano Nacional de Educação: por uma outra política educacional. 3. ed. rev. Campinas, SP: Autores Associados, 2000. 
